\title{
Plasminogen activators: a morphologist's view
}

\author{
AS TODD \\ From the Haematology Section, Department of Pathology, Ninewells Hospital and Medical School, \\ Dundee DD1 9SY, Scotland
}

Limits of space and time preclude a comprehensive review of plasminogen activators. I have therefore chosen to present a personal view of the subject, a largely morphological approach.

\section{Pragmatic classification of plasminogen activators}

Many proteases have been described as activators of plasminogen. To simplify and limit my discussion I have divided them into the following groups.

(1) Primary activators-those which by their location, mode of release, and/or affinity for other components of the fibrinolytic reaction seem specially adapted for intravascular fibrinolysis. This group consists of endothelial activator; blood activator; cadaveric activator; urokinase; and, perhaps, leucoprotease.

(2) Intermediate activators-those with normally an extravascular 1ole in fibrinolysis associated with pathophysiological mechanisms such as inflammation, healing, new growth, and immune reactions. The group includes proteases from leucocytes; from epithelial cells in sites such as cornea and cervix uteri; and from cells in culture, both normal and malignant.

(3) Non-specific activators-proteases which do not normally play a part in the digestion of fibrin but which can in vitro activate plasminogen. Trypsin is an example of these.

(4) Heterologous activators such as streptokinase.

\section{Primary activators}

It has been known since the earliest successful culture work that tissues could initiate the liquefaction of fibrin. ${ }^{1}$ Astrup and his colleagues showed that the tissues contained an activator of plasminogen, a proteolytic zymogen normally present in mammalian plasma, fibrinogen, and fibrin. ${ }^{2}$ While some of this material can be eluted with physiological salt solutions the greater part is firmly bound and can be extracted only by using concentrated solutions such as $\mathbf{M}$ potassium thyocyanate. This technique was made the basis of an assay of the 'tissue activator' of plasminogen. ${ }^{3}$

The firm binding of the activator to tissues allowed localisation to be studied on a microscopic scale. 4 When a thin section of unfixed tissue is covered by a layer of fibrin gel rich in plasminogen the zymogen is converted to plasmin wherever there is activator in the tissues. In a stained preparation areas that are rich in activator are spotlighted by the holes digested in the overlying fibrin (Fig. 1). This method, 'fibrinolysis autography', 5 shows that (1) fibrinolytic activity of tissues due to the presence of plasminogen activator is concentrated in the endothelium of blood vessels, especially that of veins and venules; (2) human arterial endothelium is on the whole less active than that of the veins, the exceptions being highly active small arteries from tissues with a high metabolic rate such as retina, myocardium, kidney; (3) severe anoxia of the tissues immediately preceding sampling greatly increases the amount of activator detectable in arterial endothelium; $;^{6}$ and (4) mechanical damage to the endothelium seems to have the same effect. ${ }^{7}$

\section{ENDOTHELIAL ACTIVATOR OF PLASMINOGEN}

IN PATHOLOGICAL PROCESSES

Quantifying plasminogen activator activity in histological preparations is difficult. Various scoring methods have been used. ${ }^{8-10}$ Nevertheless, clear trends can be seen in a number of pathological processes. In thrombosis several patterns of distribution of activator activity are seen. On the venous side of the circulation activator may be seen in relation to the endothelium whether the thrombus is attached or not. ${ }^{6}$ Where the thrombus is lying free the activity may be seen related both to vessel wall and to the surface of the thrombus, suggesting adsorption on to the fibrin. Venous thrombi and emboli may show deep in their substance strata of altered texture that are rich in activator activity. Presumably they are former surfaces buried by rethrombosis. Larger venous thrombi, thrombi from cardiac chambers, and arterial thrombi may show activator activity related to leucocytes, suggesting a 


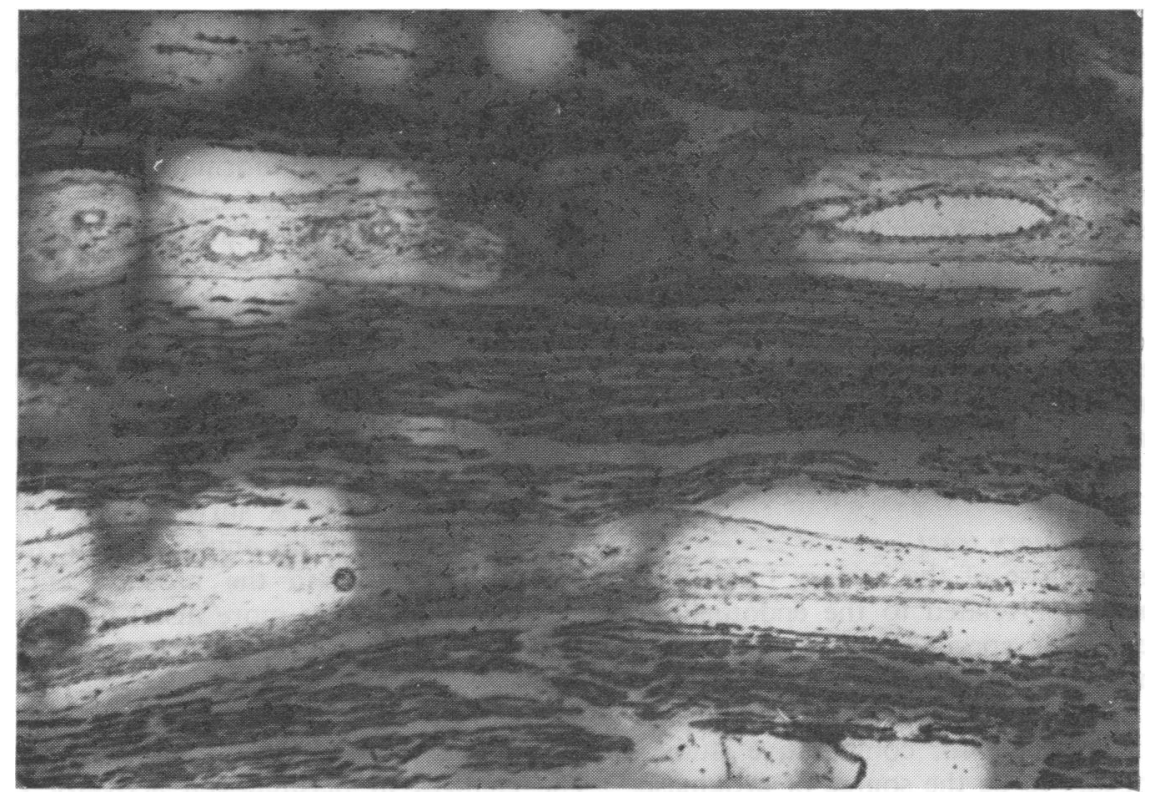

Fig. 1 Fibrinolysis autograph of nerve from limb after prolonged ischaemia. Haloes indicate centres of activator concentration and are related to blood vessels. $\times 45$.

fibrinolytic role for these cells both within and outwith the vessels. In arterial thrombi activator is mostly related to leucocytes except in the coronary arteries, where both leucocytes and endothelial cells are involved. In all these cases the experiments suggest that the thrombi persist not for want of activator but either because of lack of plasminogen or because of inhibition of plasmin activity. When the tissues are tested in the histological system plasminogen is supplied in excess and inhibitors are diluted in the fibrin gel. It should be noted that a histological method for demonstrating inhibitor of plasmin shows high concentrations of a soluble inhibitor in vascular smooth muscle. ${ }^{11}$ The presence of this component may modify the patterns shown by fibrinolysis autography.

\section{Myocardial infarction}

Experimental animal work suggests that interruption of the blood supply to the myocardium results in the loss of fibrinolytic activity from the vessels in the affected area.12 In human material fibrinolytic activity can still be detected even though the surrounding muscle cells have died. ${ }^{13}$ The differences in these observations may be that in the animal work the tissues were reperfused after release of the ligature, so that activator from the cells could be carried away, whereas in the clinical material it remains trapped in the stagnant circulation. The inference from this is that a period of ischaemia may cause massive release of plasminogen activator from the endothelium, leading to exhaustion of the local fibrinolytic mechanism, to be followed later by microthrombosis. This could explain, in fibrinolytic terms, the phenomenon of infarction without demonstrable thrombosis in a larger coronary artery.

\section{Shock lung}

A similar apparent exhaustion of fibrinolytic activity of endothelium has been demonstrated in the lungs of traumatised animals using the histological technique. ${ }^{14}$ It was found that corticosteroids prevent this loss of pulmonary endothelial activator after trauma.

\section{Bleeding problems}

Menstruation is our most physiological model of bleeding and haemostasis. The role of fibrinolysis in this process was demonstrated 65 years ago by Whitehouse, ${ }^{15}$ who showed that fragments of endometrium added to clotting blood rendered it fluid. Extraction and measurement of activator from endometrial biopsies has shown a cyclical increase in activator content, maximal at the onset of bleeding, ${ }^{16}$ and the histological technique shows a diffuse increase in the activator content of the superficial stroma. ${ }^{17}$ In cases with disordered menstruation there may often be an abnormal pattern of activator distribution. 
Changes in tissue activator concentration have recently been proposed as a factor in gastrointestinal bleeding, ${ }^{18}$ and histological preparations have suggested that in cirrhosis of the liver there is an increase in the concentration of activator in the bowel vasculature. ${ }^{19}$ The normal liver usually shows relatively little activity in histological preparations, but cirrhotic liver has a high activator content, ${ }^{4}$ concentrated in the new vessels, so that the organ as a whole may contribute to the activator in blood rather than removing it, as has been suggested by Fletcher. ${ }^{20}$ Thus in cirrhosis there may be both local and systemic mechanisms contributing to increased fibrinolysis.

\section{Tissue activator in urinary tract}

Like other tissues those of the urinary tract show plasminogen activator related to the endothelium, but the kidney is of special interest for several reasons. It contains an endothelial structure of very standard size and arrangement, the glomerulus, making it an ideal organ for comparative studies. Secondly, it appears to be the source of urokinase, another primary activator; thirdly, fibrin (and thus fibrinolysis) play an important part in renal disease. Endothelial activator is demonstrable in arteries, veins, and the glomeruli. ${ }^{21}$ Glomerular activity is variable but is increased in fat embolism and in cases where a normal kidney has been exposed to hyper- tension by a Goldblatt phenomenon. ${ }^{22}$ Detailed examination of autographs has suggested a direct relationship between endothelial damage and fibrinolytic activity (Fig. 2). The histological technique gives little information about urokinase; only a few preparations show medullary activity that could be ascribed to urokinase in the tubules.

The autographs shed some light on the causation of local and systemic bleeding in prostatic disease. Contrary to older beliefs, the epithelium of the prostate does not seem to release plasminogen activator, and increased fibrinolytic activity from metastatic prostatic carcinoma is shown to be related to the stroma of the metastasis rather than the neoplastic cells. ${ }^{7}$ A survey of the plasminogen activator content of the epithelia of the male genital tract shows none in the prostate but gradually increasing activity as more distal tissues are examined, with most plasminogen activator in urethral glands. ${ }^{23}$

\section{Inflammation}

The changes in plasminogen activator content of tissues in inflammation has been studied with the histological technique. In acute experiments with rats the vessels most involved in early inflammation (the venules) were those which contained most plasminogen activator. ${ }^{17}$ More prolonged experiments have shown a loss of activator from the

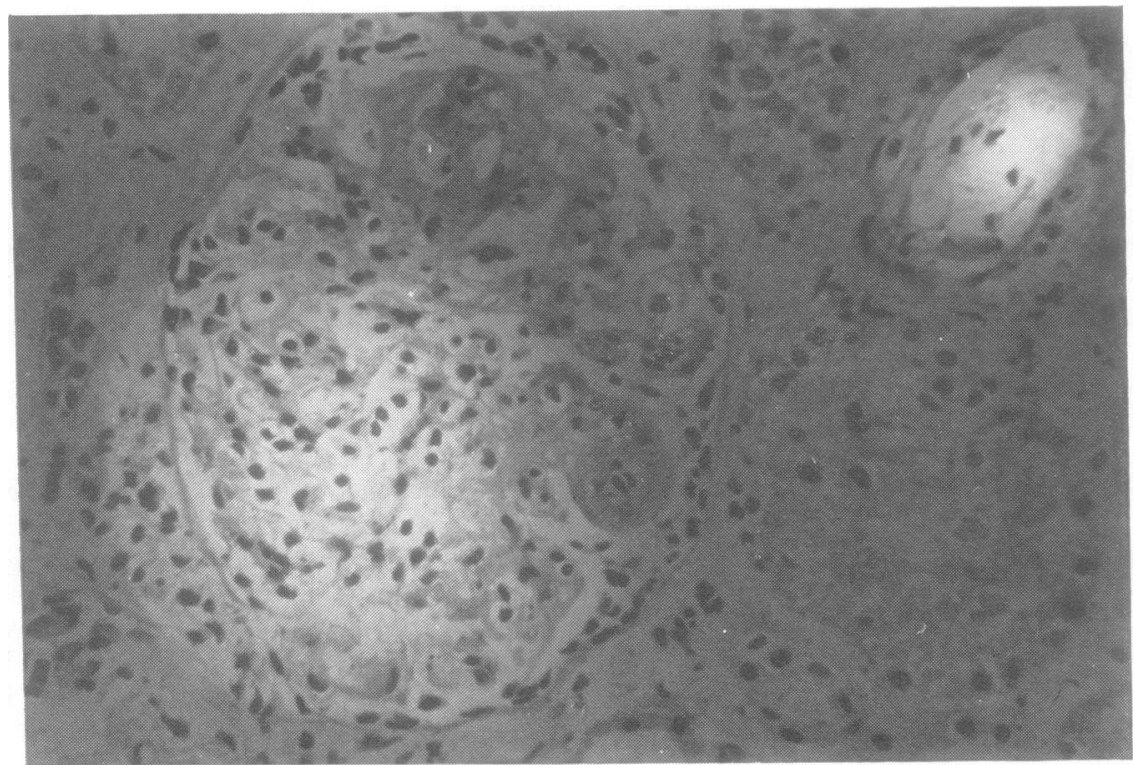

Fig. 2 Glomerulus damaged by hypertension following contralateral renal arterial obstruction showing fibrinolysis confined to undamaged part of capillary tuft. Fibrinolysis autograph. $\times 766$. 
endothelium of inflamed tissue and the appearance of an inhibitor of fibrinolysis. ${ }^{24}$ In the inflammation associated with the Arthus reaction leucocytes will activate plasminogen, but only after they have escaped from the blood vessels. ${ }^{25}$

\section{CADAVERIC ACTIVATOR OF PLASMINOGEN}

This activator (sometimes referred to as vascular activator of plasminogen) has been studied by several groups. ${ }^{26-28}$ It is obtained by perfusing the blood vessels of the leg with buffered saline solutions. Probably it is either the same as, closely related to, or derived from, endothelial activator. The activator has been partly purified and characterised with respect to physical properties, effect on artificial substrates, and susceptibility to various inhibitors. Some partial antigenic identity with urokinase and blood activator of plasminogen has been reported.29

We have used antibodies to cadaveric activator (raised in rabbits) as a reagent for immunofluorescence microscopy and, on a smaller scale, to measure the amount of cadaveric activator in blood. Immunofluorescence microscopy of human tissues with this antibody shows localisation of the antigen to the endothelium, coinciding with the lysis seen in the autograph preparations but more extensive, including lining of arteries and capillaries. ${ }^{27}$ This suggests that although the antibody can neutralise the enzymic activity of cadaveric activator most of its affinity may be for the 'non-active' part of the protein or for an associated protein acting as precursor, carrier, or subunit. In thrombi strata of antigen concentration are seen corresponding to the lines of activator activity seen in autograph preparations (Fig. 3). The use of the antibody for measuring the (presumed) endothelial activator protein in blood gives puzzling results. Considerable amounts of antigen are demonstrable, but changes in antigen concentration after exercise are minor compared with the increases in euglobulin lysis times (Table 1). In acute illness modest increases over normal are demonstrable (Table 2) paralleling the massive changes in factor VIII antigen ${ }^{30}$ a protein also known to be concentrated in endothelium. ${ }^{31}$

BLOOD ACTIVATOR OF PLASMINOGEN The fibrinolytic activity in blood, measurable by

Table 1 Changes in mean plasma concentrations of vascular activator antigen (measured by Laurell immunoelectrophoresis) and in activator activity (measured by euglobulin lysis times) after exercise in 10 normal subjects

\begin{tabular}{lrr}
\hline & Before exercise & After exercise \\
\hline Activator antigen (\% 'normal') & 109 & 122 \\
Lytic activity (arbitrary units) & 6 & 74 \\
\hline
\end{tabular}

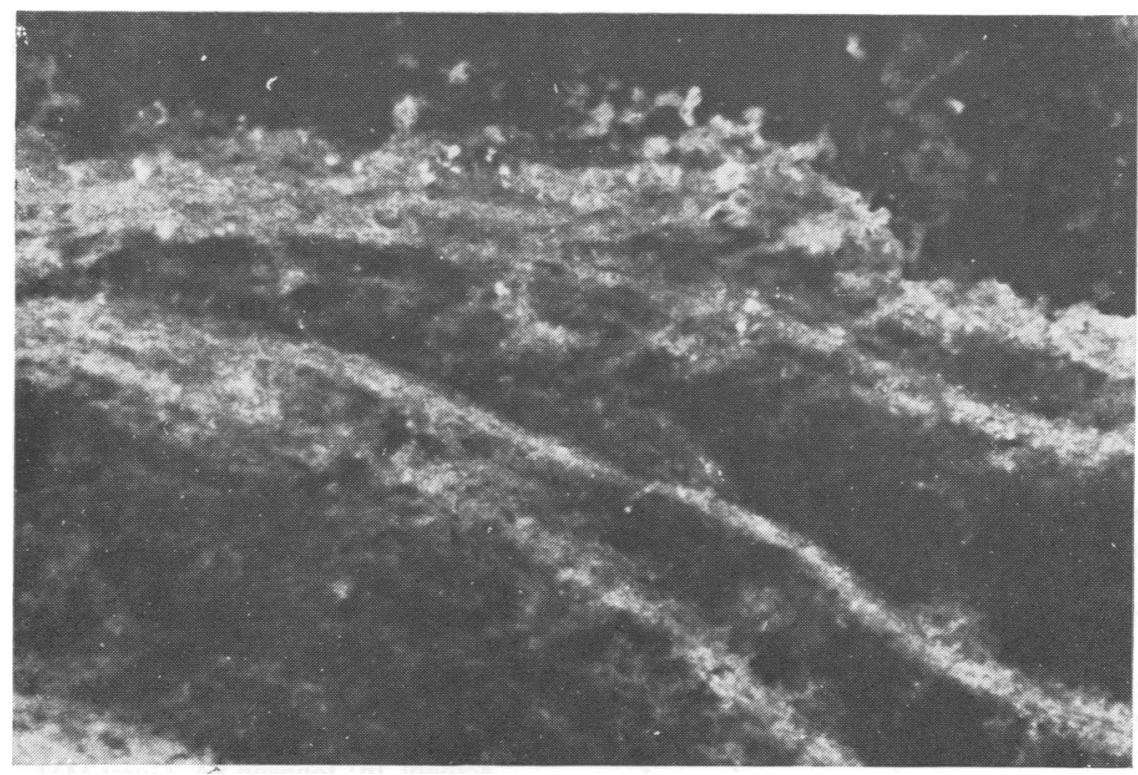

Fig. 3 Immunofluorescence microscopy for vascular activator antigen on part of a femoral vein thrombus, showing laminar distribution of activator protein. Indirect immunofluorescence. $\times 300$. 
Table 2 Plasma levels of activator antigen $(\%$ of normal pool standard, measured by the Laurell technique) after myocardial infarction

\begin{tabular}{lrllll}
\hline & No. & Mean & $S D$ & Range & Significance \\
\hline Normals & 9 & 111 & \pm 45 & $60-160$ & - \\
After infarction & 14 & 196 & \pm 35 & $95-237$ & $\mathrm{p}<0.001$ \\
\hline
\end{tabular}

diluted blood clot or euglobulin lysis methods, is thought to be initiated by a soluble activator in the blood. I expect that this activator will have been discussed in detail by Professor Ogston (see page 5). Suffice it to say that activity of this sort can have at least two sources: (1) the release of activator from endothelium (the 'extrinsic activator system'); (2) by generation from precursors in the blood after contact activation of Hageman factor (intrinsic activator system). The interrelationship of these activators with the endothelial activator and with urokinase will be discussed below.

\section{UROKINASE}

This is the last of the 'primary activators' to be mentioned. It has been more intensively studied chemically than the others, but despite this its exact role remains obscure. Culture experiments show that it can be synthesised by the kidney. ${ }^{32}$ Recent work using antibodies to purified urokinase show, as with the cadaveric activator, considerable amounts of the protein in blood, again not varying in parallel with the fibrinolytic activity. ${ }^{33}$ Tests with this antibody have shown immunofluorescence localisation of urokinase to the renal tubules. ${ }^{27}$

\section{Intermediate activators}

Time does not allow much discussion of intermediate activators except to draw attention to the interesting suggestions that such proteases, presumably by their effect on plasminogen, may have important effects on the growth of cells, particularly in malignancy. ${ }^{34}$

\section{Conclusion}

The four 'primary' activators-from endothelium, blood, cadaveric eluates, and urine-may all be detected within the circulatory system. It seems important that direct comparisons of these activators should be made, particularly of their physical characteristics (molecular weight, electrophoretic mobility); immunological identity; subunit structure; effect on artificial substrates; and susceptibility to inhibitors. No single test can be a valid criterion of identity and the work is bedevilled by 'complexing', attachment to carrier proteins, dissociation into subunits, and the artefacts of preparation. Nevertheless, I hope these problems can be overcome by exchange of materials between laboratories, thus allowing a coherent account of the relationship between the primary activators to be written.

Another matter that seems worth further study is the role of membrane lipids in the operation of plasminogen activators. It does seem that the most stable and vigorous activator is that found in the endothelial cells. Could these characteristics be due to the positioning of the enzyme in a phospholipid matrix? The extraction experiments using thiocyanate suggests that the enzyme is a 'membraneassociated' protein. Support for this view comes from the chloroform effect, ${ }^{35}$ the effect of iso-amyl alcohol $^{\mathbf{3 6}}$ on fibrinolytic activity of blood, and the inhibition of fibrinolysis by lipaemia. ${ }^{37}$ It is generally believed that chloroform neutralises protein inhibitors of plasmin in the blood. It could, however, also modify the disposition of lipids and phospholipids around the activator molecules. In brief, is a specific phospholipid matrix necessary for the optimal activity of plasminogen activator, just as a similar arrangement is necessary in the intrinsic blood coagulation system?

Like thrombosis, fibrinolysis is a local event, modified by factors in the circulating blood, and important components of the system are concentrated in the endothelial cells. It seems profitable therefore to continue the topographical approach to problems of fibrinolysis, using the improved techniques that biochemistry and immunology are providing.

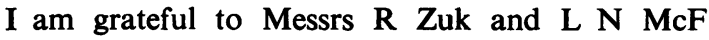
Hargreaves for antigen measurements, to $\mathrm{Mr} \mathrm{R}$ Fawkes for photography, and to Mrs E S Cargill for preparing the typescript.

\section{References}

1 Lambert RA, Hanes FM. Characteristics of growth of sarcoma cultivated in vitro. J Exp Med 1911; $13: 495-503$.

${ }^{2}$ Astrup T, Permin PM. Fibrinolysis in the animal organism. Nature 1947;159:681-2.

${ }^{3}$ Albrechtsen OK. The fibrinolytic activity of human tissues. Br J Haematol 1957;3:284-91.

4 Todd AS. The histological localisation of fibrinolysin activator. J Pathol Bacteriol 1959;78:281-3.

5 Todd AS. Fibrinolysis autographs. Nature 1958; 181 :495-6.

6 Todd AS. The blood vessel wall and fibrinolytic activity. In: Johnson SA, Guest MM, eds. Dynamics of thrombus formation and dissolution. Philadelphia: Lippincott, 1969:321-39.

7 Todd AS. The tissue activator of plasminogen and 
thrombosis. In: Walker W, ed. Thrombosis and anticoagulant therapy. Edinburgh: Livingstone, $1961: 25-31$.

${ }^{8}$ Kwaan HC, Astrup T. Localisation of fibrinolytic activity in the eye. Arch Pathol 1963;76:595-601.

${ }^{9}$ Pandolfi M, Nilsson IM, Robertson B, Isacson S. Fibrinolytic activity of human veins. Lancet 1967; 2:127-8.

10 Cunnliffe WJ, Dodman BA, Dodman EA, Webster JA. A method for the quantitative assessment of tissue fibrinolysis. In: Davidson JF, Samama MM, Desnoyers PC, eds. Progress in chemical fibrinolysis and thrombolysis, vol 1. New York: Raven Press, 1975:241-7.

${ }^{11}$ Noordhoek Hegt V, Brakman P. Histochemical study of an inhibitor of fibrinolysis in the human arterial wall. Nature 1974;248:75-6.

12 Cherry GW, Opie LH. Decreased myocardial fibrinolytic activity following temporary ischaemia and reperfusion. Thromb Diath Haemorrhag 1975; 34:210-5.

${ }^{13}$ Todd AS. In: Wright IS, Koller F, Strenli F, eds. Thrombolytic activity and related phenomena. Thromb Diath Haemorrhag 1961;6:Suppl 1;287.

14 Risberg B. Fibrinolysis in the lung. Acta Chir Scand (Suppl) 1975;458:16.

15 Whitehouse HB. The physiology and pathology of uterine haemorrhage. Lancet 1914;1:877-85, 951-7.

${ }^{16}$ Albrechtsen OK. The fibrinolytic activity of the human endometrium. Acta Endocrinol 1956;23:207-18.

17 Todd AS. Localisation of fibrinolytic activity in tissues. Br Med Bull 1964;20:210-2.

${ }^{18}$ Cox HT, Poller L, Thomson JM. Gastric fibrinolysisa possible aetiological link with peptic ulcer. Lancet 1967;1:1300-2.

${ }^{19}$ Oka K, Tanaka K. Local fibrinolysis of oesophagus and stomach as a cause of hemorrhage in liver cirrhosis. Thromb Res 1979;14:837-44.

${ }^{20}$ Fletcher AP, Biederman O, Moore D, Alkjaersig N, Sherry S. Abnormal plasminogen-plasmin system activity (fibrinolysis) in patients with hepatic cirrhosis: its cause and consequences. $J$ Clin Invest 1964;43:681-95.

21 Todd AS, Nunn A. Fibrinolytic activity in tissues and thrombi. In: Tissue factors in the homeostasis of the coagulation-fibrinolysis system. Turin: Unione Chimica Medicamenta, 1967:57-76.

22 Todd AS. Endothelium and fibrinolysis. Bibl Anat 1973;12:98-105.

${ }^{23}$ Kester RC. The distribution of plasminogen activator in the male genital tract. $J$ Clin Path 1971 ;24:726-31.

${ }^{24}$ Ryan TJ, Nishioka K, Dawber RPR. Epithelialendothelial interaction in the control of inflammation through fibrinolysis. Br J Dermatol 1971;84:501-15.

${ }^{25}$ Förster O. Proteases in inflammation. In: Bertelli A, Houck JC. Inflammation, biochemistry and drug interaction. (International congress series, 188). Amsterdam: Excerpta Medica, 1969:53-65.

${ }^{26}$ Aoki N, von Kaulla KN. Dissimilarity of human vascular plasminogen activator and human urokinase. $J$ Lab Clin Med 1971;78:354-62.

27 Todd AS, Hargreaves LNMcF. Identification of plasminogen activator in tissue. In: Davidson JF, Samama MM, Desnoyers PC, eds. Progress in chemical fibrinolysis and thrombolysis, vol 1. New York: Raven Press, 1975:217-24.

${ }^{28}$ Pepper DS, Allen R. Isolation and characterisation of human cadaver vascular endothelial activator. In: Davidson JF, Rowan RM, Samama MM, Desnoyers $\mathrm{PC}$, eds. Progress in chemical fibrinolysis and thrombolysis, vol 3. New York: Raven Press, 1978: 91-8.

${ }^{29}$ Mackie MJ, Bennett B, Ogston D. A comparison of plasminogen activators. Scot Med J 1979;24:102.

${ }^{30}$ Hargreaves LNMcF, Nicoll DAP, Todd AS. The use of a macroscopic aggregation test for von Willebrand factor as an indicator of endothelial damage. Thromb Res 1977;11:101-2.

${ }^{31}$ Bloom AL, Giddings JC, Wilks CJ. Factor VIII on the vascular intima. Possible importance in haemostasis and thrombosis. Nature (New Biol) 1973;241 :217-9.

32 Bernik MB, Kwaan HC. Plasminogen activator activity in cultures from human tissues. J Clin Invest 1969;48:1740-53.

${ }^{33}$ Shakespeare $M$, Wolf $\mathbf{P}$. The demonstration of urokinase antigen in whole blood. Thromb Res 1979; 14:825-35.

${ }^{34}$ Reich E. Plasminogen activator: secretion by neoplastic cells and macrophages. In: Reich E, Rifkin DB, Shaw E, eds. Proteases and biological control. Cold Spring Harbor NY. Cold Spring Harbor Laboratory, 1975:333-41.

${ }^{35}$ Christensen LR. The activation of plasminogen by chloroform. J Gen Physiol 1946;30:149-57.

${ }^{36}$ Monkhouse FC, Milojevic S, Schmitt A. Significance of plasma inhibitor(s) in the control of fibrinolytic (plasmin) activity in blood. Thromb Diath Haemorrhag 1972;28:367-75.

37 Greig HBW. Inhibition of fibrinolysis by alimentary lipaemia. Lancet 1956;2:16-8. 